\title{
La justicia de la tortura. Variaciones sobre el tema ${ }^{* *-\cdots * * *-\cdots * * * * *}$
}

\section{The justice of torture. Some remarks}

\author{
RESUMEN
}

En fechas recientes, varios filósofos y juristas se han replanteado la posible justificación de la tortura, reabriendo la "Caja de Pandora" que se estimaba absolutamente sellada tras el consenso jurídico internacional de la segunda posguerra. En este trabajo se analizan la filosofía de la tortura, sus variantes consecuencialistas, así como algunas de las estrategias argumentativas utilizadas para reclamarle un espacio de legitimidad en nuestras modernas democracias. Comienza revisando dos de las obras más importantes contra la quaestio escritas durante el siglo XVIII para enfatizar su incompatibilidad fenomenológica con el derecho. A continuación, se introduce en algunas discusiones suscitadas tras las conclusiones de la Comisión Landau de Israel en 1989, donde el debate sobre la tortura fue reabierto. Luego de recordarnos la posición de Jeremy Bentham al respecto, el autor critica cuidadosamente sendas estrategias desarrolladas con la finalidad de legitimarla en la actualidad. Su conclusión, sin embargo, es tajante: la tortura, si es una imposición deliberada de sufrimiento contra un sujeto indefenso, sigue siendo tortura, sea cual sea su motivo o los fines que se persigan, y no puede justificarse.

Catedrático de Filosofía del Derecho, Dipartimento di Scienza e Storia del Diritto, Università "Magna Graecia" di Catanzaro (Catanzaro, Italia).Contacto: mlatorre @ unicz.it ORCID: 0000-0002-9844-2397.

** Recibido el 9 de enero de 2020, aprobado el 12 de junio de 2020.

Para citar el artículo: La Torre, M. La justicia de la tortura. Variaciones sobre el tema. En Revista Derecho del Estado, Universidad Externado de Colombia. N. ${ }^{\circ} 47$, septiembre-diciembre de 2020, 3-29.

DOI: https://doi.org/10.18601/01229893.n47.01

*** Edición original: La giustizia della tortura. Variazioni sul tema. En Materiali per una Storia della Cultura Giuridica. Vol. xuIv, n. ${ }^{\circ}$ 1, 2014, 3-29. Traducción de Francisco M. MoraSifuentes (Universidad de Guanajuato). Se traduce con permiso expreso de la editorial Il Mulino y del autor. ORCID: 0000-0002-9881-2730.

**** Este escrito es el resultado de una estancia de investigación en la Universidad de Münster, Alemania, como Fellow del Kolleg-Forschergruppe "Theoretische Grundfragen der Normenbegründung in Medizinethik und Biopolitik", durante la primavera de 2011. El autor agradece al Prof. Thomas Gutmann y a los colegas del Kolleg-Forschergruppe, tanto por su generosa hospitalidad como por las provechosas discusiones. El texto usa argumentos y materiales utilizados en el libro escrito conjuntamente con M. Lalatta Costerbosa, Legalizzare la tortura? Ascesa e declino dello Stato di diritto, Bologna, Il Mulino, 2013. El Abstract fue elaborado por el traductor. 
PALABRAS CLAVE

Tortura, abolicionismo, utilitarismo, consecuencialismo, deontología.

ABSTRACT

The "Pandora Box" on the issue of justifying torture, which has been considered sealed since the international legal consensus was reached in the post-Second World War period, has been recently reopened by quite few philosophers and legal scholars. This work analyses the philosophy of torture, its consequentialist variants, as well as some of the argumentative strategies used to make room for legitimacy in our modern democracies. It begins by reviewing two of the most relevant works against the torture, written in the $18^{\text {th }}$ Century, aiming at emphasizing its phenomenological incompatibility with the law. The reopening of the "Pandora Box" took place afterward Israel Landau Commission conclusions in 1989. After reminding us of Jeremy Bentham's position in this regard, the author insightfully criticizes other strategies developed in order to legitimize it today. His conclusion, however, is emphatic: torture, if it is a deliberate imposition of suffering against an individual, continues to be torture, whatever its motive or ends may be, and cannot be justified.

KEYWORDS

Torture, Abolitionism, Utilitarianism, Consequentialism, Deontology. SUMARIO

1. La reacción contra la tortura. 2 . El retorno de la tortura. La ruptura del tabú. 3. Utilitarismo y consecuencialismo. La filosofía de la tortura. Referencias.

\section{LA REACCIÓN CONTRA LA TORTURA}

La tortura ha sido parte integrante de nuestros sistemas de derecho positivo, de nuestra cultura jurídica, durante muchos siglos. Con todo, no han faltado dudas, perplejidades y críticas desde el comienzo de su recepción jurídica. La tortura, más allá del hecho jurídico positivo, siempre ha sido una práctica muy controvertida, nada pacífica. Encontramos dudas en la Retórica de Aristóteles (1377a), o en varios pasajes en la obra de Cicerón (por ejemplo, en Pro Silla, 78, o en sus famosas "Verrinas"), así como en algún otro escritor romano (pienso en Séneca y en Valerio Máximo). Asimismo, en la Institutio oratoria de Quintiliano (v, 4), donde la información extraída con tormento por su ambigüedad se equipara con la fama y los rumores ("fama 
atque rumores"). Para Antífona de Ramnunte (v, 31-32) esta información no es fiable, porque el hombre torturado dirá finalmente lo que el torturador quiere que diga, sea o no cierto. "Etiam inocentes cogit mentiri dolor", dice molesto Publilio Siro (Sententiae, 174).

San Agustín, en su De civitate dei (xIx, 6), es hostil a la quaestio, y todo el cristianismo, cuyo símbolo es la cruz, atroz instrumento de tortura, transmite un sentimiento de horror hacia la crueldad de esa práctica inhumana. La oposición a la tortura se vuelve más virulenta con el humanismo renacentista (en tal sentido, debemos recordar la actitud de rechazo de Juan Vives, el profesor valenciano de Oxford y amigo de Tomás Moro y de Erasmo) y, sobre todo, al comenzar el Barroco (valga, por todas, la crítica de Hobbes en el capítulo XIV de El Leviatán), que culminó finalmente en el debate abolicionista de la Ilustración.

Existe un primer libro contra la tortura, muy lúcido, escrito en el siglo XVII por un jesuita alemán, la Cautio criminalis de Friedrich von Spee. El libro del padre jesuita (que data de 1631) se presenta como un tratado y análisis crítico de los juicios contra las brujas. Sin embargo, su núcleo es la justificación del rechazo contra la tortura como práctica habitual del juicio penal. El texto es elegante, los argumentos presentados son elocuentes y sutiles, pero, sobre todo, sus páginas destilan un sentido de legalidad y piedad.

La tortura -dice von Spee- es omnipotente: el ser humano sometido a ella se encuentra o está totalmente, absolutamente, en manos del torturador que puede hacer lo que desee con él. Nada queda de la persona torturada: su cuerpo y su alma están quebrados, doblados, "retorcidos", al servicio de los otros que lo hacen temblar y gritar de dolor. En el nombre mismo, "tortura", hay un "mal". Se tortura "retorciendo"; y el resultado es un "mal". La tortura no soporta el "derecho". Es la tiranía máxima que un individuo puede sufrir, destruye la subjetividad misma del ser humano, y solo por esta razón es incompatible con el derecho.

La crítica de la tortura como tiranía extrema (por lo tanto, como una práctica que viola radicalmente el derecho natural) -"la tortura tiene un poder casi total", escribe von Spee ${ }^{1}$ - será retomada y desarrollada cincuenta años después por un gran jurista y filósofo del derecho, alemán también, Christian Thomasius, que escribe una obra titulada explícitamente contra la tortura (Dissertatio de tortura et foris christianorum prohibenda), proponiendo la prohibición sistemática del tormento en el proceso judicial. Aquí, empero, también me gustaría recordar especialmente el trabajo de un autor austríaco, Joseph von Sonnenfels, y el de un jurista español, Juan Pablo Forner.

1.2. Entre los escritos que preparan la abolición de la tortura en los Estados de la Europa de la Ilustración tiene especial valor y relevancia el ensayo

1 Von SPEe, F. I processi contro le streghe (Cautio criminalis). FoA, A. (ed.). Roma: Salerno, 2004, 345. 
Ueber die Abschaffung der Folter, publicado por primera vez en Zúrich en 1775. Este escrito -que es de Josef Sonnenfels ${ }^{2}$ - no es muy conocido hoy en día y es difícil de encontrar. No obstante, tuvo un profundo efecto en la discusión del momento, siendo leído y comentado cuidadosamente. Sus páginas nos ofrecen un inteligente y articulado compendio de los principales argumentos ya dirigidos contra la práctica de la tortura, no sin algún elemento de originalidad.

La primera y fundamental crítica que encontramos en este trabajo es aquella -tradicional pero siempre poderosa- basada en el valor de la información que la tortura podría proporcionarnos. La información obtenida de la confesión mediante la tortura no tiene -lo sabemos- ningún valor cognitivo más allá de certificar que la persona torturada no pudo resistir más el dolor que le fue infligido ${ }^{3}$. La tortura ataca y hiere profundamente la naturaleza humana. Quiebra la autonomía y la conciencia del sujeto, y lo convierte en un simple animal. Instrumentaliza, "deforma", de hecho, su cuerpo en contra de su mente, dirige sus sentimientos contra su razón, utiliza su sufrimiento para abrumar y silenciar sus argumentos ${ }^{4}$. Aquí cesa violentamente la función de protección y amparo de la autoridad estatal. ¿Es esta la protección prometida por el soberano, "Das wäre also Behutsamkeit?". La tortura no es más que la lucha de la naturaleza humana contra sí misma ${ }^{5}$. La persona torturada se ve obligada a prestar su cuerpo a una atroz lucha contra la naturaleza ${ }^{6}$.

La tortura rompe y anula el contrato social entre soberano y súbdito. Con ella la promesa de protección hecha por el soberano se desvanece. Ante él, no hay más espacio seguro para el ciudadano. Los peligros que la tortura representa para la vida individual son más serios que aquellos contra los cuales el contrato social pretende protegernos. La tortura pone sobre la cabeza del sujeto muchos más peligros de los que deberían servir para evitarlo o protegerlo, y para cuya protección se ha firmado el contrato social y, por tanto, se ha acordado ponerse bajo la protección del gobierno y sus leyes ${ }^{7}$. El simple cálculo prudencial no permite a la comunidad política exponer a sus miembros al riesgo de la tortura. La muy dudosa utilidad que pueda tener es superada, al ponderar los intereses en juego, por el gravísimo daño que se infligiría a los torturados, por no mencionar el daño causado a la seguridad pública. En

2 Es de subrayarse, en el contexto de la Ilustración del siglo xVIII, la carga radical y la riqueza cultural de la obra de Sonnenfels (quien también fue autor de obras teatrales exitosas); incluso, hay quienes sugestivamente lo colocan junto a Beaumarchais. Cfr. vON ARNETH, A. R. Beaumarchais und Sonnenfels. Wien: Wilhelm Braumüller, 1868.

3 Von Sonnenfels, J. Ueber die Abschaffung der Folter. En Sonnenfels gesammelte Schriften. Vol. 7. Wien: Mit von Baumeisterischen Schriften, 1785, 51-52.

$4 \quad$ Ibid., 84.

$5 \quad$ Ibid., 82.

$6 \quad$ Ibid., 86.

$7 \quad$ Ibid., 81-82. 
tal escenario, la seguridad pública se vería comprometida por la amenaza de tortura que ahora aplica a los ciudadanos. ¿No es uno de los derechos de dominio público infligir tales males generalizados a sus asociados?

La tortura es un castigo, y uno de los más crueles. Pero no se puede infligir un castigo sin juicio previo. Sin embargo, la tortura precede al juicio, lo anticipa, y en esencia lo hace superfluo.

Pero no es cierto que sea un castigo -objetan los defensores del tormento-. Es solo un método especial de interrogar al delincuente o al sospechoso. Sin embargo, "la realidad del sufrimiento", responde Sonnenfels, "se rebela contra tal argucia de leguleyo y no puede ser silenciada por ingeniosos juegos de palabras". No hay eufemismo que se sostenga contra el grito de dolor del hombre torturado ${ }^{9}$. ¿Se puede silenciar el dolor con una casuística decisión? $¿$ ¿Se puede engañar a la sensibilidad con los argumentos de "esos doctos que aman la humanidad", "diese menschenfreundliche Rechtsgelehrten"? ${ }^{10}$. Al escucharlos, el bien común se parece a un dios pagano, a un ídolo monstruoso que solo puede ser satisfecho derramando ríos de sangre inocente. La tortura trastorna y subvierte la noción de responsabilidad y culpabilidad, ya que la inocencia no salva a los torturados de la ruina, de la degradación. Pero entonces, ¿qué sentido puede tener en una sociedad que admite el tormento querer mantenerse inocente? Si la inocencia no nos salva, ¿quién querrá seguir siendo inocente? Y ello es así porque la inocencia no impedirá el más cruel de los castigos ${ }^{11}$.

La naturaleza de la tortura y su calificación no se derivan de la naturaleza y la calificación del delito por el que se puede infligir. La naturaleza de la tortura sigue estando definida por la intensidad y la calidad de la coacción que ejerce, y por los peligros para los sujetos y la res publica sujeta esa coacción. La gravedad de cualquier delito cometido por la persona torturada no altera la naturaleza odiosa y cruel de la práctica ${ }^{12}$.

Para Sonnenfels, la tortura debería estar excluida incluso en casos de alta traición ${ }^{13}$. Porque hay demasiadas cosas que siguen siendo inciertas y poco fiables con respecto a la información y las condiciones de aplicabilidad de tal práctica coercitiva. La coerción es siempre poco fiable: "So sehr ist immer bei dem Zwange alles unzuverlässig"14. Y en este punto se distancia de Voltaire. Sin embargo, y contra la opinión de Beccaria, acepta la "Zwangsfrage", el

8 Ibid., 95. Para una propuesta moderna sobre este tema, véase BRUNKHORST, H. Torture and Democracy. En Clucas, B., Johnstone, J. G. y Ward, T. (eds.), Torture: Moral Absolutes and Ambiguities. Baden-Baden: Nomos, 2009, 73 ss.

9 Von Sonnenfels. Ueber die Abschaffung der Folter, cit., 98.

10 Ibid., 100.

11 Ibid., 102.

12 Ibid., 113-114.

13 Ibid., 114-115.

14 Ibid., 115. 
interrogatorio realizado con violencia, cuando se trata de descubrir a los cómplices del culpable. En este caso - argumenta- el sujeto no está obligado a dañarse a sí mismo y, por tanto, no puede hacer valer su derecho a resistirse a la coacción. Esto también se aplica a los casos de "Sicherheit des gemeinen Wesens" $" 15$, los casos de seguridad de la res pública, de situaciones de emergencia en las que dicha seguridad está en juego. En esos casos, el autor austriaco sí recurriría a la tortura. Si en una situación tan urgente y peligrosa el delincuente es torturado, la culpa es solo suya, por negarse a responder espontáneamente a las preguntas del investigador. "Wenn er sich weigert [...], so ist es seine Schuld, nicht die Schuld der Richter, nicht der Gesetze" ${ }^{16}$.

Es posible que las excepciones que Sonnenfels admite para la abolición de la tortura estén diseñadas para que su propuesta abolicionista sea menos radical y, por lo tanto, capaz de obtener la aprobación de la corona. Sin embargo, el hecho es que el abolicionismo del jurista de los Habsburgo no es absoluto. Deja una puerta abierta para el uso de la tortura en situaciones de emergencia, que son hoy -como sabemos- las que invocan para justificar la revisión de la consolidada prohibición absoluta de la tortura. Sea como fuere, la crítica de Sonnnenfels a la tortura es tan aguda y articulada, y sobre todo tan general en su alcance, que se puede dudar de la consistencia e incluso de la sinceridad de su posible conclusión.

El Discurso de la tortura de Juan Pablo Forner ${ }^{17}$ se remonta a finales del siglo XVIII, unas décadas después de la obra de Sonnenfels. Las críticas a la tortura en este texto son fundamentalmente similares a las del autor centroeuropeo, pero aún más decisivas y radicales. A pesar de los años que han transcurrido desde su publicación no han perdido -considero- nada de su fuerza. "Ante todo, la tortura", dice Forner, "es incierta en sus resultados ya que induce a la gente a mentir indiscriminadamente para escapar del sufrimiento". "Reflexionad si una opresión que induce a la mentira es proporcionada para hallar la verdad"18. Para escapar del dolor, uno está dispuesto a decir cualquier cosa: lo que es verdad y lo que no lo es. Y entre la verdad y la falsedad, en la confusión por los gritos de dolor, será difícil deshacer el enredo.

La tortura altera la balanza de la justicia y corrompe la dialéctica procesal, pues le da al acusador mucho más poder que al acusado. La acusación con tormento es capaz de aplastar cualquier defensa. La tortura es la expresión de la voluntad tiránica. Esto -dice el jurista español-tiene una raíz histórica, ya que la tortura en las ciudades de los ciudadanos y de los hombres libres fue introducida por los emperadores romanos, Augusto y Tiberio. Es decir,

15 Ibid., 118.

16 Ibid.

17 Forner, J. P. Discurso sobre la tortura. Mollfulleda, S. (ed.). Barcelona: Crítica, 1990.

18 Ibid., 190. 
la tortura se da en el derecho romano al finalizar la libertad republicana con la afirmación del Principado, de un régimen tiránico. La utilidad y la seguridad pública son el fundamento exigido para la tortura no pueden separarse del interés de la justicia. "La mayor utilidad de los hombres está en que no padezcan lo que no merecen" 19 . La seguridad pública es la certeza del goce de los propios derechos, garantía jurídica. "Reflexionad [...] si protege la seguridad de los ciudadanos una ley que puede conducir al suplicio, con igual infamia, al inocente que al facineroso" 20 .

La tortura por su naturaleza es una práctica cruel y despiadada, pues su objetivo inmediato es causar un sufrimiento intolerable. "No hay tormento que cause dolor, y el dolor de tan exquisita vehemencia que los mismos pragmáticos la califican de atroz y comparable a una pena cruelísima, y los médicos la declaran perjudicial a la salud" ${ }^{21}$. Esto la hace diferente de cualquier otro castigo, ya que no es realmente concebible como una situación permanente y duradera en el tiempo.

La última crítica es que existe incompatibilidad fenomenológica entre la tortura y el derecho. La tortura no puede soportar las reglas, escapa a las normas. Su carácter abusivo y excesivo no se ajusta a la normalidad y previsibilidad de la disposición normativa. "Las imprecisiones del dolor son irreducibles a reglas fijas [...]. Así, el tormento esencialmente debe producir en cada uno de los sentimientos relativos a su constitución particular del cuerpo y del espíritu" 22 . La incertidumbre radical y su incompatibilidad con las normas no solo se refieren a los posibles resultados de la tortura, sino también a sus métodos y a las situaciones en que se aplica. En los anales de la jurisprudencia no se conoce una ley suficientemente detallada sobre los casos, los medios y mitos de la tortura. "Jamás se publicó una ley que determinase con individualidad en qué casos se debía echar mano del tormento, contra qué personas, hasta qué grado, de qué manera" ${ }^{23}$. La legalización de la tortura solo puede significar el reconocimiento y la autorización de la arbitrariedad y del abuso. No limita la tortura; sino que le da legitimidad y cobertura moral.

\section{EL RETORNO DE LA TORTURA. LA RUPTURA DEL TABÚ}

2.1. A pesar de la prohibición general de la tortura, alcanzada en los sistemas jurídicos positivos de los Estados, empezando por la crítica de la Ilustración, y luego en el derecho internacional tras la trágica experiencia de las dictaduras totalitarias del siglo $\mathrm{xx}$, es cierto que la tortura ha sido repetida. A veces,

19 Ibid., 174-175.

20 Ibid., 190.

21 Ibid., 188.

22 Ibid., 187.

23 Ibid., 166. 
incluso, masiva y sistemáticamente practicada por funcionarios o agentes de los propios Estados liberales y democráticos. Valga por todos el caso de la Argelia francesa en los años cincuenta, cuando la tortura se utilizó de forma generalizada y deliberada como estrategia para derrotar la resistencia del Frente Nacional de Liberación argelino ${ }^{24}$. Incluso entonces, sin embargo, no se tuvo el coraje de reclamar abiertamente su moralidad, y mucho menos su legalidad. Si alguien tortura, normalmente lo hace en secreto, lo oculta, porque se avergüenza de ello. La Caja de Pandora de la legitimidad sellada por el liberalismo del siglo XIX no fue reabierta. Es más, permanecía bastante cerrada. Así fue al menos hasta los años ochenta, cuando se creó en Israel la Comisión Landau (que lleva el nombre del jurista que la presidió) para que se pronunciara sobre la legitimidad de las prácticas de interrogatorio de la policía y los servicios secretos israelíes socavaban por los palestinos sospechosos de actividades terroristas.

Las conclusiones de la Comisión Landau ponen en duda la previa y consolidada certeza abolicionista: "Actual torture [...] would perhaps be justified in order to uncover a bomb to explode in a building full of people" (p. 60) $)^{25}$. A pesar del tono cauteloso, con estas palabras ahora se rompe el tabú de la prohibición absoluta. Se ha reabierto la Caja de Pandora. Y es en torno a la opinión de esta Comisión que cierta "ciencia jurídica" -por boca de los "doctos amantes de la humanidad", como diría Sonnenfels- vuelve a ejercer su finura argumentativa, discerniendo sutilmente el tema y congratulándose de una posible relegalización del tormento. Este es el caso, por ejemplo, de Michael Moore, un académico estadounidense. A este último le sigue Winfried Brugger, un estudioso alemán.

Para que pueda hablarse de la legitimidad -e incluso el "deber"- de la tortura algunas de nuestras instituciones morales más profundas deben alterarse radicalmente. Para lo cual no bastan los argumentos generalmente de naturaleza consecuencialista. Lo que es necesario es reconfigurar el hecho mismo de la tortura. Es decir, es necesario proporcionar una fenomenología diferente que sea tolerable o aceptable a nuestro sentido moral. Por eso, aunque sea básicamente un argumento consecuencialista o utilitarista el que se utiliza para su justificación ética -para que funcione y sea pertinente-, también se necesita una retórica correspondiente y congruente, y, sobre todo, una narrativa capaz de representar un acontecimiento distinto del que se percibe como una crueldad extrema ejercida contra sujetos indefensos. Hay que contar otra historia, en la que el indefenso se convierte en agresor y la

$24 \mathrm{Al}$ respecto, léase el dramático testimonio de AlLEG, H. La question. Paris: Gallimard, 1958.

25 Sobre este punto, cfr. GinBar, Y. Why Not Torture Terrorists? Moral, Practical, and Legal Aspects of the 'Ticking Bomb' Justification for Torture. Oxford: Oxford University Press, $2010,171 \mathrm{ss}$. 
agresión extrema en una última pero posible defensa. Esta forma de proceder (un "giro" de los hechos) queda bien ejemplificada en lo que Winfried Brugger, profesor de Derecho Público y de Filosofía del Derecho de la Universidad de Heidelberg, ha estado diciendo durante muchos años.

2.2. Escribe Brugger: "La imposición del sufrimiento es un mal; con cada acto de este muere no solo en los torturados, sino también en cada uno de nosotros, un pedacito de humanidad, civilización y dignidad. Pero el ojo de la justicia también debe ver a la víctima del secuestro"26. Es decir, reconocemos el mal que se inflige con la tortura, y no solo a los torturados, sino también a cada uno de nosotros en términos morales. Adviértase, por tanto, que la atención se desplaza inmediatamente desde la situación cierta y presente en la que se da la tortura, y en la que obviamente hay una víctima (la persona torturada) y un agresor (el torturador), a una situación posible y anterior en la que la relación entre víctima y agresor se configura de tal manera que la persona torturada se convierte ahora en agresor y no ya en la víctima. La tortura sería entonces una forma de restablecer y reequilibrar la justicia entre la víctima y el agresor, abriendo los ojos hasta ahora vendados de la justicia al sufrimiento de la víctima (que ya no está aquí en primer lugar y es eminentemente la persona torturada). La dignidad se sopesa contra la dignidad, como la vida se sopesa contra la vida, como, por ejemplo, en el caso de un asesinato cometido en defensa propia o en estado de necesidad.

Así, el argumento de Brugger se desarrolla en cuatro movimientos. Primero, se vuelca la intuición moral (y la correspondiente narración) para que la tortura sea un caso de maldad extrema o absoluta. El mal más grave ahora es abstenerse de la tortura, y resulta de la prohibición de las fuerzas del orden de torturar. Esta inversión se lleva a cabo cambiando el foco de atención de la situación y del delito de tortura al delito anterior. Aquí ahora hay una víctima y un agresor diferente a la que hay en la situación de tortura, y la impotencia ante la agresión que se redefine y se reescribe como "injusticia". Es injusto que el agresor haya secuestrado a un inocente y no revele su escondite, por lo que es igualmente "injusto" que el Estado no haya protegido al secuestrado antes y siga sin protegerlo, no lo localice ni lo libere. La injusticia del acto criminal original, el secuestro, se transmite a la ley que obstaculiza el trabajo de las fuerzas policiales, prohibiéndoles el trato inhumano y cruel del secuestrador.

En este caso -dice Brugger- hay una laguna "axiológica", es decir, una situación en la que la moral invita al derecho a hacerse de lado para dar paso al criterio ético. En virtud también de la analogía con la legítima defensa y el estado de necesidad que actúan como causas de justificación de conductas que de otro modo serían punibles, y en particular de la autoridad generalmente

26 BRUgGer, W. Das andere Augen. Folter als zweischlechteste Lösung. En Frankfurter Allgemeine Zeitung. 10 de marzo, 2003, 8 (cursivas en el original). 
otorgada a los sistemas legales para suspender o equilibrar derechos con el fin de salvar o salvaguardar otros derechos, el vacío axiológico requiere ser llenado por el criterio ético que impone en el caso concreto: la ejecución de tratos inhumanos o crueles, o la tortura.

Si no fuera así, si se evadiera la imposición de ese trato en el caso concreto, el contrato fundamental que se da entre el Estado y el ciudadano, por el cual aquel asume la tarea de proteger la vida y la dignidad de los ciudadanos, también fracasaría. Si el Estado abandona a la víctima (el secuestrado) en manos del agresor (el secuestrador), si no es capaz de liberarlo, es necesario también que aplique una coacción extrema contra el agresor, entonces el ciudadano estará exento de la obligación de obedecer al Estado. En particular, en este caso concreto el individuo puede cuestionar legítimamente el monopolio de la violencia otorgado al Estado, ya que ese supuesto monopolio, por una parte, es incapaz de proteger al ciudadano y, por otra, le prohíbe hacer justicia (por tanto, también torturar) por sí mismo.

De esta forma: de la evidencia de la injusticia que desplaza la atención del hecho de la tortura a un hecho delictivo anterior, pasamos a la constatación de una "Bewertungslücke", de una laguna valorativa o axiológica, y luego, a través de la reconstrucción de una posible analogía entre el asesinato y la tortura, a afirmar la derogación de la prohibición de la tortura sin excepciones también establecida por la ley, so pena de romper finalmente el pacto fundamental entre el Estado y los ciudadanos sancionado en la Constitución. Al prohibir el uso de la tortura, el Estado se convertiría a sí mismo en cómplice del criminal -añade, tras la estela de Brugger, Reinhard Merkel, otro jurista alemán-. De hecho, "[a]quellos que no ven, sin embargo, los costos regulatorios relacionados con hacer el Estado un cómplice objetivo de un asesinato, no entienden el problema"27.

La prohibición positiva de la tortura es cierta y absoluta. Las disposiciones pertinentes en el derecho internacional y en el derecho interno no dejan lugar a dudas. El propio Brugger no pude escapar a esta conclusión. La cuestión de la legalidad de la tortura se resuelve de manera definitiva y taxativa en el derecho positivo: "Die Antwort aller einschlägigen Rechtsnormen ist: nein, nie!" ${ }^{28}$. Tampoco puede sustraerse a esa conclusión Reinhard Merkel, que reconoce lo siguiente con respecto a la cualificación normativa de la tortura en Alemania: "En este país, la tortura también está prohibida sin excepción alguna, de conformidad con la letra del derecho internacional" ${ }^{29}$. No obstante, "muchos juristas y ciudadanos -dice Brugger inmediatamente- consideran

27 Merkel, R. Folter als Notwehr. En Die Zeit. 13 de marzo, 2008.

28 BRUGGER, W. Freiheit und Sicherheit. Eine staatstheoretische Skizze mit praktischen Beispielen. Baden-Baden: Nomos, 2004, 57.

29 Ibid. 
esta conclusión absurda y evidentemente injusta" ${ }^{30}$. La intuición moral ha sido invertida: ya no es el uso de la tortura lo que es claramente injusto, sino su prohibición. Porque la legislación que teje el grueso manto de tal prohibición sería una recompensa para el crimen y el delincuente; protegería al agresor, no a la víctima.

Con todo, todavía hay alguna esperanza. Si prima facie la prohibición parece absoluta, examinada desde el punto de vista de la víctima, incluso desde una perspectiva puramente jurídica -nos dice Brugger-, es "menos cierta y nada obligatoria". Si examinamos las normas, en particular las de la legislación policial alemana, relativas a la legitimidad del asesinato selectivo de un agresor que pone en peligro la vida de personas inocentes, tenemos que ver -continúa el profesor- que tal acción, es decir, el asesinato selectivo para salvar vidas inocentes, "finaler Rettungsschuss", está ciertamente autorizada. Si argumentamos por analogía, podríamos entonces llegar a la conclusión de que, si una acción tan ofensiva como el asesinato se permite a las fuerzas policiales bajo ciertas condiciones, no vemos por qué bajo las mismas condiciones no se podría permitir el uso de la tortura, que entre otras cosas es menos ofensiva que el asesinato. En cualquier caso, si la aplicación de las disposiciones sobre el homicidio selectivo a la tortura no puede apoyarse por analogía, al menos por analogía será posible apoyar la existencia de una laguna o incoherencia sistémica, ya que dos casos similares (de hecho, muy parecidos) se tratan y regulan de manera diferente. Por tanto, uno podría argumentar que no es razonable la prohibición absoluta de la tortura en un sistema que admite el asesinato para salvar vidas inocentes. De hecho, Brugger no habla de irrazonabilidad en este sentido, sino más bien de "Fehlbewertung", de evaluación incorrecta o imperfecta ${ }^{31}$.

La "evaluación incorrecta", que hace que la prohibición sea incoherente o irrazonable, depende del hecho de que la tortura a la que se refiere la prohibición tiene dos características que, no obstante, no concurren en el caso de que la vida de personas inocentes esté en juego. La tortura está absolutamente prohibida porque se considera que sus víctimas están indefensas, mas sin tener en cuenta los crímenes de los que son responsables. Pero en el caso de la tortura, digamos, de un secuestrador que no quiere revelar el escondite del secuestrado, las dos características que acabamos de mencionar no están presentes. El secuestrador detenido no está indefenso (ya que sigue dañando al secuestrado, manteniéndolo en cautiverio y negándole la libertad), y también es un criminal, que por lo tanto tendría la obligación de detener la ejecución de su plan criminal, así como el deber de cooperar con las fuerzas del orden y la ley. En tal constelación de acontecimientos, por tanto, existe una situación en la que la dignidad del agresor (lo que nos impediría someterlo a la

$30 \quad$ Ibid., 58.

31 Ibid., 60. 
tortura) entra en conflicto con la dignidad de la víctima, que sigue siendo violada por el agresor, aun si es detenido; y que solo puede ser redimida y restaurada mediante el uso de la fuerza, es decir, la tortura, a fin de obtener la información necesaria para sacar al secuestrado de su estado de cautiverio.

A fin de evitar la derogación de la prohibición de la tortura que resultaría del "conflicto de dignidades" y que su ponderación sea demasiado amplia, Brugger propone conceder la posibilidad de aplicar medidas de interrogatorio violento solo bajo ciertas condiciones específicas. Debe tratarse de un peligro (1) claro, (2) inmediato y (3) grave para la (4) vida o (eventualmente) integridad física de una persona inocente; (5) el peligro en cuestión debe ser provocado por un atacante identificado, que es (6) la única persona capaz de desactivar o evitar el peligro reconduciendo su conducta dentro de los límites de la ley, y (7) debe haber una obligación legal para el agresor de hacerlo, donde (8) la aplicación de violencia física es el único medio para obtener información que ofrezca alguna posibilidad de éxito para la desactivación del peligro ${ }^{32}$.

Algunos consideran que la relativización de la prohibición de la tortura es incompatible con el Estado de derecho. Este último sería un Estado que, en principio, se compromete a utilizar un mínimo de fuerza en sus relaciones con sus ciudadanos. Sin embargo, un Estado de derecho -objeta el estudioso alemán- sigue siendo un Estado, y debe seguir siéndolo para ser efectivo, pues sin esto su dimensión normativa sería solo un espacio vacío. Y un Estado como tal tiene como presupuesto definicional que es capaz de proteger la vida de sus asociados. La capacidad de protección es lo que define al Estado como tal y, por ende, también es el núcleo esencial de esa forma específica de Estado que es el Estado de derecho. Aquí hay una tensión más o menos oculta entre la forma accidental o contingente y su naturaleza esencial: el Estado de derecho quiere reducir la violencia, pero la fuerza estatal sigue siendo profundamente violencia, por lo que su reducción excesiva podría poner en peligro y perjudicar la existencia misma del Estado.

El Estado de derecho -nos dice Brugger- padece una "antinomia interna": "Rechtsstaat steht gegen Rechtsstaat" ${ }^{33}$. Para resolver esa antinomia, Brugger tiene poco que decirnos; excepto que no necesariamente debe suavizarse endureciendo la estructura normativa y civilizadora del Estado de derecho con su principio de minimizar la fuerza. La antinomia también debería considerarse cuidadosamente desde la perspectiva de la esencia del Estado como monopolio de la violencia. Si este falla en su premisa de protección, entonces la anarquía será legítima, la justicia por propia mano de los ciudadanos, a quienes se ha decepcionado en sus expectativas de protección o necesidades de seguridad. Esto podría llevarnos de regreso al pasado más obscuro de la ley o el estado de naturaleza, a un estado salvaje: "ein wahrer Rückschritt

32 Ibid., 62.

33 Ibid., 68. 
ins Mittelalter oder der 'Naturzustand'!" 34 . Dicho de manera más explícita: no es el uso de la tortura sino su prohibición lo que nos lleva de regreso a la Edad Media...

El Estado tiene el derecho de ejercer coacción, aplicar sanciones, y, por tanto, de utilizar la violencia, allí donde sus ciudadanos estén en peligro o sus derechos sean violados. La violencia es parte esencial e integral de la actividad estatal. ¿Por qué entonces el Estado no podría o debería usar la tortura? Este es el fondo de la tesis de Brugger y su argumento concluyente. Como el Estado es (utiliza) coacción, entonces el Estado también es tortura (y puede y debe utilizarla). Cualquiera que niegue esta conclusión no reconocería, y, de hecho, negaría la esencia del Estado, haciendo suyas, en última instancia, las razones de la anarquía.

2.3. El argumento de Brugger, con todo, no es válido. La tortura no es el tipo de coerción que sea objeto de un sistema jurídico, o, mejor, no está incluido en la coacción, o en la violencia, de la cual el Estado tiene el monopolio. O dicho otra forma: de la asunción de que el Estado tiene el monopolio de la violencia no se sigue ni implica que se permita al Estado cualquier violencia. La violencia estatal como garantía del derecho y los derechos es una fuerza que se ejerce sobre la conducta y el comportamiento, no sobre las ideas y la conciencia de los sujetos. La policía puede dispersar legítimamente una reunión de personas violentas, y la coerción ejercida aquí se dirige hacia la conducta de los manifestantes. Es una fuerza "mecánica" -por así decirlo- la que se usa en este caso, una fuerza que se dirige al comportamiento externo. La tortura es muy diferente: aquí no es el comportamiento del sujeto o sus movimientos el objeto de la coerción, sino su voluntad interior. La tortura quiere romper la voluntad del hombre torturado, jugar a poner su cuerpo contra su mente y obligarlo a hacer y decir lo que realmente no quiere decir ni hacer. Es por esto que la tortura sufrida va acompañada de un sentimiento de vergüenza y humillación: se deriva de la conciencia de que la tortura afirma con extrema evidencia de haber tenido que sufrir violencia íntima.

La violencia legítima del derecho no viola la intimidad del sujeto, no causa la división radical de su cuerpo y su mente, típica de la experiencia de la tortura. La fuerza del derecho no viola ni rompe la dignidad humana. Puede dañar la integridad física del ciudadano y reducir su libertad de movimiento, pero no lo considera un simple objeto de acción estatal, una "cosa", una simple "herramienta". Esta actitud de respeto (aun en el mismo uso de la fuerza) ya no es posible en la tortura, en donde además de la integridad física y la libertad personal está en juego el libre albedrío del sujeto. Este ya no necesita capacidad o autonomía sino, más bien, obedecer una orden, debe padecer y sufrir. La tortura funciona según la lógica de esa máquina 
atroz que Kafka imaginaba en su cuento In Der Strafkolonie [En la colonia penal], en donde el delincuente es castigado por la incisión en el cuerpo, en la piel, de la ley quebrantada.

El mandato del torturador no un acto lingüístico, es todo menos una pregunta, quaestio, toda vez que no se está capacitado para responder negativamente. Es una pregunta que solo acepta el sí. Respecto a ella, no puede pensarse en la alternativa del "sí" o del "no". No es una pregunta para dirigir o influir el comportamiento. Más bien, es una pregunta que ya está respondida de manera vinculante. Es como un procedimiento quirúrgico con el que se extrae un órgano. Lo único es que aquí el órgano que se extrae es la voluntad del sujeto. Es un abuso sobre el cuerpo de un sujeto vivo por parte de otro ${ }^{35}$.

Es similar a la violación. "Es ist wie eine Vergewaltigung", como dice Jean Améry ${ }^{36}$. Nuestro cuerpo ya no garantiza la separación del yo. El cuerpo del torturador entró con fuerza en el cuerpo del torturado. También se podría decir que el torturador trata a los torturados como una caja fuerte que tiene que ser forzada ${ }^{37}$.

Por tanto, la tortura es una forma de violencia infinitamente superior, más invasiva y cualitativamente diferente a la fuerza manifestada en el ejercicio de la coacción estatal que acompaña la ejecución de las normas jurídicas. La sanción estatal no implica ni requiere crueldad; pero la tortura es crueldad reincidente y persistente. Por otro lado, si no fuera así, es decir, si la tortura y la coacción estatal coincidieran o fueran superponibles, siguiendo el argumento de Brugger llegaríamos a resultados absurdos y francamente insostenibles.

El argumento del profesor alemán va demasiado lejos. Es decir, una vez aceptado, se extiende y se aplica a casos en los que Brugger -creo- hubiera dudado en justificar o invocar el uso de la tortura. De hecho, si la coacción y la tortura fueran equivalentes (como afirma el estudioso alemán), entonces, por ejemplo, en el caso de la reunión de personas violentas, en lugar de una "cargada", la autoridad policial podría detener a dos o tres manifestantes y someterlos a tortura, todo ello con la intención de inducir a sus camaradas, al resto de los manifestantes, a desistir de su actitud violenta. Es probable que en este caso la tortura sea más "convincente" y efectiva que la cargada policial. ¿Por qué entonces el Estado no podría utilizarla, en particular, cuando los derechos fundamentales de los ciudadanos (por ejemplo, el derecho a la propiedad o libertad de movimiento) están en grave peligro? O piénsese en la evasión de impuestos: en lugar de prever una sanción financiera o una pena de prisión para quienes evaden al fisco, uno podría acudir a la aplicación de

35 Cfr. Brecher, B. Torture and the Ticking Bomb. Oxford: Blackwell, 2007, 81.

36 АмÉRY, J. Jenseits von Schuld und Sühne. Bewältigungsversuche eines Überwältigten. Stuttgart: Klett-Cotta, 1977, 56.

37 Cfr. GILEAD, A. Torture and singularity. En Public Affairs Quarterly. Vol. XIX, 2005, 164. 
"un poco" de tortura ${ }^{38}$. Es probable en este caso que los efectos positivos para las arcas estatales sean significativos. Ahora, en vista del estado de la deuda pública y sus numerosas consecuencias negativas para toda la nación (sobre el bienestar de millones de ciudadanos), y ante el grave peligro de una quiebra de las finanzas públicas estatales, ¿por qué la autoridad debe dudar en administrar "un poco" de sufrimiento al evasor de impuestos?

\section{UTILITARISMO Y CONSECUENCIALISMO. LA FILOSOFÍA DE LA TORTURA}

3.1. Filosofar sobre la tortura es una empresa difícil y altamente cuestionable. Hay cosas que nos degradan al tener que considerarlas o "mirarlas" y cuya "teoría" en todos los casos es grotesca e incluso obscena. Hay actos cuya injusticia extrema no nos permite detenernos para reflexionar y deliberar sin correr el riesgo de ser despreciables. En resumen, como se ha dicho, "existen riesgos al tratar la tortura como un tema de filosofía moral" 39 . Y, sin embargo, encontramos filósofos más o menos distinguidos que han ejercido o ejercen su inteligencia para discutir y justificar la práctica del tormento. Entre estos destaca Jeremy Bentham.

En la gran cantidad de escritos del filósofo inglés se ha encontrado un fragmento sorprendente dedicado al tema de la tortura. Sabemos que Bentham, por sus reflexiones y sus planes de reforma, había encontrado inspiración en la obra de Cesare Beccaria. El autor italiano se refirió al principio de utilidad como el criterio rector para muchas de sus consideraciones; sin embargo, no elaboró o profundizó más en esta idea. Este es el punto de partida de la investigación filosófica de Bentham, y a partir de tal referencia genérica al principio de utilidad del pensador italiano desarrolla esa teoría moral articulada y poderosa que es el utilitarismo. Bentham es el verdadero fundador del utilitarismo y su propagandista más efectivo e influyente.

El utilitarismo en el pensamiento inglés es el resultado de ese movimiento más general y de época que es la Ilustración. La Ilustración y el utilitarismo van de la mano, al menos así parece suceder en el trabajo de Beccaria y, en muchos sentidos, también en el de Bentham. La razón, la racionalidad, la reflexividad -a la que apela la Ilustración- parecen indicarnos que la utilidad de la sociedad, la felicidad del mayor número es el fin y, por tanto, el criterio al que deben orientarse la conducta humana y sus reglas. Con todo, el conflicto entre la Ilustración y el utilitarismo, entre el principio de razón como autodeterminación y el principio de utilidad como cálculo prudencial, está latente, manifestándose claramente en la cuestión de la legalidad y legitimidad

38 Cfr. SCHROEDER, D. A child's life or a 'little bit of torture'? State-sanctioned violence and dignity. En Cambridge Quarterly of Healthcare Ethics. Vol. xv, 2006, 2.

39 Mayerfield, J. In defense of the absolute prohibition of torture. En Public Affairs Quarterly. Vol. xxII, 2008, 112. 
de la tortura. Mientras Beccaria es un enemigo tenaz de esta práctica, y la rechaza en todo supuesto, Bentham la acepta sorprendentemente y la reclama bajo ciertas condiciones, criticando abiertamente al autor italiano. La utilidad general en Bentham prima sobre la piedad y los derechos individuales; algo que, por otra parte, nunca podría haber sido considerado por Beccaria, cuya negativa a la tortura, aunque motivada por argumentos consecuencialistas genéricos, está fuertemente anclada en una perspectiva (y en una sensibilidad) con rasgos deontológicos.

El utilitarismo de Bentham entra en conflicto con la Ilustración -puede afirmarse- cuando no deja espacio en su teoría para la noción de derechos fundamentales. Sabemos que el filósofo inglés fue enemigo de las declaraciones de derechos de las revoluciones liberales. Hay un núcleo autoritario en la visión de Bentham, una obsesión con el mandato y la obediencia, la centralidad de la soberanía y el control jerárquico -todas ellas son cuestionadas o amenazadas, considera, por los nuevos derechos fundamentales que se proclaman como anteriores y superiores al mandato político, al gobierno y a la soberanía misma. Sabemos también que Bentham era contrario a cualquier reconstrucción normativa de la comunidad política en términos contractualistas. Ni el contrato social, ni los derechos fundamentales son para él la fuente del orden político, más bien lo son la fuerza y el hábito ${ }^{40}$. "The origination of governments from contract is a pure fiction, or in other words, a falsehood" (Anarchical Fallacies, 279). "All governments that we have any account of have been gradually establishes by habit, after having been formed by force" (ibid., 280).

Pero la hostilidad a la noción de derechos del hombre, así como a la de política -a la que Bentham acusa incluso de ser parte de un "terrorist language" (ibid., 239)-, se debe a un empirismo radical (que debe mantener que esos derechos no son entidades reales en el mundo), y sobre todo a una opción iuspositivista radical, según la cual los derechos solo pueden ser consecuencia de órdenes positivas (por tanto revocables) emitidas por el soberano: "No such things as rights anterior to the establishment of government" (ibid., 230). Por estas dos razones será necesario concluir que los derechos humanos, en tanto derechos naturales, son una expresión carente de sentido: "natural rights is simple nonsense: natural and imprescriptible rights, rhetorical nonsense -nonsense upon stilts" (ibid., 230).

Los derechos también colisionan con el principio de utilidad: como posiciones normativas deberían ser capaces de resistir el cálculo prudencial

40 Este es el punto decisivo en el cual diverge la doctrina de Bentham de la de Beccaria. Este último adopta, en cambio, la concepción contractualista: "las leyes son o deberían ser pactos de hombres libres". Beccaria, C. Dei delitti e delle pene. Pisapia, G. D. (ed.). Milano: Giuffrè, 1973, 7. Al respecto, cfr. HART, H. L.A. Essays on Bentham. Jurisprudence and Political Theory. Oxford: Clarendon, 1982, cap. segundo. 
de las utilidades involucradas. La libertad de religión, digamos, como título normativo es válida incluso si es contraproducente con respecto a la felicidad del mayor número. El sentido del derecho fundamental es precisamente ese, el de ofrecer al individuo un título para oponerse a la comunidad y a las preferencias agregadas de este; de modo que la preferencia individual, su autonomía, no puede ser computada y reabsorbida en una figura y práctica colectiva. En otras palabras, los derechos individuales, debido a su naturaleza eminentemente ética, no pueden ser absorbidos por un número colectivo. No son ponderables. No son valores que puedan tratarse mediante un cálculo aritmético. Esto, sin embargo, es precisamente lo que Bentham, debido a su teoría consecuencialista, no puede concebir y aceptar absolutamente. No hay derecho que pueda oponerse a la utilidad o a la felicidad general. Y no hay ningún derecho que pueda ser renunciado o derogado cuando la utilidad así lo requiera. "As there is no right which ought not to be maintained so long as it is upon the whole advantageous to the society, that is should be maintained, so there is no right which, when the abolition of it is advantageous to society, should not be abolished" (ibid., 239).

Veamos ahora cómo procede Bentham respecto a la tortura. Aquí -debe subrayarse- vuelve a abrir una puerta que acaba de cerrarse en el pensamiento filosófico-jurídico, y la visión que se vislumbra inmediatamente se convierte en su propio y verdadero pasaje. La forma de argumentar del autor inglés es singular, al menos en el contexto en el que escribe sus páginas sobre la tortura, pero a la luz de la controversia actual adquiere un carácter ejemplar. Su primer movimiento es el de la redefinición. La tortura se redefine como una compulsión violenta y dolorosa para llevar a cabo u omitir cierta conducta: "La tortura, como la concibo, ocurre cuando una persona es sometida a un sufrimiento físico violento para obligarla a hacer algo o desistir de hacer algo, el que lo sufre, una vez que se hace, o se abstiene de hacer, esa cierta cosa, se detiene inmediatamente [Torture as I understand it it is when a person is made to suffer any violent pain of body to compel him to do something or to desist from doing something which done or desisted from the penal application is immediately made to cease]"41.

Dicho esto, el argumento de Bentham aún procede desde una perspectiva conceptual y fenomenológica, sin recurrir inmediatamente a consideraciones utilitarias desde el comienzo. La tortura -dice para empezar- es una práctica recurrente; es un castigo habitual, ordinario, y no más cruel que otros. Piénsese en el caso de la fuerza que generalmente se usa contra los niños díscolos: "If a parent having put a question to his child and upon the child's obstinately refusing to answer whips him till complies, this too is neither

41 Twining, W. L. y Twining, P. F. Bentham on torture. En Northern Ireland Legal Quarterly. Vol. xxIv, 1973, 30. 
more nor less than torture" ${ }^{42}$. Si un niño no responde a su padre y este lo reprende a correazos hasta que ceda, se trata de una práctica que Bentham asume como usual, normal, legítima y no cruel. Se trata de una forma de tortura contra la cual ni Bentham ni otros "gentlemen" -al parecer- tienen nada que objetar. La tortura, por tanto -y ese es el núcleo de esta narrativa-, se practica, asiduamente, de hecho, con el consenso y la aprobación general.

$\mathrm{Su}$ paso posterior es el siguiente. La tortura -dice Bentham- es una especie de pena, pero, a diferencia de esta, tiene un propósito mucho mejor, más limitado o determinado, y, por tanto, se presta menos para el abuso. No queda claro cuál sea el propósito de encarcelar al delincuente: la relación entre el hecho (el encarcelamiento) y su efecto (aunque siempre vago) en este caso es hipotético e indeterminado. En la tortura, de otra parte, la cadena causal entre el hecho y el efecto es mucho más definida y precisa (proporcional) que cualquier otra forma de castigo. De hecho, la tortura se infligirá única y exclusivamente con el grado de coerción y sufrimiento que sea necesario para inducir al delincuente a una determinada acción u omisión. En la prisión, sin embargo, se viola la proporcionalidad, ya que el propósito del castigo no está del todo claro. Por tanto: "If Torture deserves to be reprobated, Punishment does still more" ${ }^{\text {43 }}$. Entonces, si se va a condenar la tortura, con mayor razón tendría que serlo la pena de prisión.

En este punto podría objetarse, no obstante, que la detención es predeterminada en su duración, y, por tanto, no se presta en tal sentido al abuso del perpetrador, mientras que la tortura es necesariamente indeterminada tanto en cuanto a la duración como a la intensidad del sufrimiento infligido. Bentham admite esto: es cierto, la tortura es indeterminada. ¿Pero de quién es la culpa? $\mathrm{Su}$ indeterminación se produce en cualquier caso por la conducta del delincuente que insiste en no responder las preguntas formuladas o no acceder a las solicitudes que se le dirigen. En realidad, dado que el delincuente se niega a operar como tendría el poder y el deber de hacerlo, es él quien causa el daño. El delito principal es el suyo. El daño de la tortura es secundario y posible en comparación con el mayor daño, en este caso cierto y seguro, que es causado por la resistencia y obstinación del delincuente: "If then having it in his power to do it he is obstinate and in despite of justice persists in refusing to do it; when is the harm done?" ${ }^{44}$. Cada vez que el delincuente (o, mejor todavía, el acusado o el sospechoso) resiste y persiste en no complacer al torturador, es él, el torturado, quien está cometiendo un delito, y un delito adicional. "Every moment that he persists in his refusal he commits a fresh offence" ${ }^{45}$. Estamos aquí lejos -en mi opinión- de la sensibilidad liberal

\footnotetext{
$42 \quad$ Ibid., 310.

43 Ibid., 311.

44 Ibid., 312.

45 Ibid.
} 
de un Beccaria, para quien la crueldad es un umbral insuperable para todo operador de justicia.

Por otra parte, vale la pena detenerse un momento más en la equivalencia que Bentham establece entre la tortura, por un lado, y las penas o sanciones negativas, por otro. En realidad, la tortura es muy diferente de cualquier sanción negativa y especialmente de la prisión, ya que no trata de influir o determinar la conducta del sujeto, limitando la esfera del ejercicio libre. Tampoco se trata de anular su libertad de voluntad, sensibilidad y conciencia de una vez por todas (como en el caso de la pena de muerte). Al contrario, se trata de eliminar directa y absolutamente la libertad de querer, mientras mantiene su conciencia y capacidad de sentir (esta última explotada específicamente para doblegar su libertad de voluntad ${ }^{46}$.

Con la tortura, es la misma confianza primitiva en el mundo la que se cae a pedazos: ya no sabemos en qué ni con quién podemos contar. En las manos del torturador cualquier cosa puede ocurrirme. Ya nada ni nadie puede ayudarme. El sentimiento es el de la incertidumbre radical sobre el mundo que me rodea y la conciencia de ser totalmente sometido. Jean Améry lo dice muy bien, cuando recuerda su experiencia de tortura: "Puedes hacer conmigo lo que tú quieras [Man wird mit mir anstellen, was man will]"47.

La pena privativa de libertad, el asesinato y la tortura son tres formas muy diferentes de sancionar. También se podría argumentar plausiblemente que la tortura no puede ser realmente una sanción jurídica, si esta (la sanción) se concibe como un mal predecible, determinable y determinado en intensidad y duración. Dado que la tortura debe actuar como un mal inesperado, o incluso inimaginable, de la que no es posible prever un método concreto de aplicación. Está sujeta -como dice Klaus Günther-a una "inmanente falta de límites"48.

3.2. Muy citado, significativamente también por John Yoo en su Memorandum del $1 .^{\circ}$ de agosto de $2002^{[49]}$, es un artículo de Michael Moore, que apareció en la Israel Law Review de 1989, en el número dedicado al informe de la Comisión Landau ${ }^{50}$. Moore se declara iusnaturalista, pero en su artículo de 1989 no duda en apoyar la legitimidad, bajo ciertas condiciones, de la tortura de inocentes. La tortura del "culpable" le parece menos problemática.

46 Cfr. Bielefeldt, H. Menschenwürde und Folterverbot. Zur Aufweichung des Folterverbots. Berlin: Deutsches Institut für Menschenrechte, 2007, 12.

47 АмÉrY. Jenseits von Schuld und Sühne, cit., 55.

48 GüNTHER, K. Folter kennt keine Grenze. En Die Zeit. 13 de marzo, 2008.

49 Véase Standards of conduct for interrogation under 18 U. S. C. $\$ \$ 2340-2340$. En GreEnBERG, K. J. (ed.), The Torture Debate in America. Cambridge: Cambridge University Press, 2006, 355. (El Memorandum -dirigido a Alberto R. Gonzales, consejero jurídico del presidente George W. Bush- está formalmente firmado por Jay Bybee, un colega de John Yoo -quien, sin embargo, es el redactor real del documento- en el Office of Legal Counsel del Departamento de Justicia estadounidense).

50 Moore, M. S. Torture and the balance of evils. En Israel Law Review. Vol. XXIII, 1989, 280 ss. 
El verdadero dilema moral surge, en todo caso, cuando se trata de torturar al "inocente". Por ejemplo, al hijo o la madre del posible terrorista. Incluso en este caso Moore llega a reconocer la legalidad de la tortura. No le tiembla la mano ni la voz para afirmarlo. Por el contrario, agrega que puede hacerlo sin negar su autoproclamado iusnaturalismo.

La tesis de Moore es que, respecto a la tortura del inocente, valga prima facie la postura deontológica de prohibición, siempre y cuando no se alcance un umbral tan alto de consecuencias negativas de la prohibición que una perspectiva consecuencialista deba reemplazar a la actitud deontológica. $\mathrm{Si}$, por ejemplo, el peligro de muerte por la bomba de tiempo que ha sido puesta por el terrorista amenaza la vida de una sola, dos o diez personas, la actitud deontológica y la prohibición de la tortura relacionada con ella siguen siendo válidas. Sin embargo, si se llega a un umbral N (por ejemplo, cien vidas humanas -aunque Moore ya no es preciso en este punto-), entonces la postura deontológica se ve derrotada, por lo que la prohibición de la tortura del inocente debe ceder ${ }^{51}$.

Moore no está en condiciones de decirnos cuándo se alcanza el umbral, lo que significa que pasaremos repentinamente de la perspectiva deontológica de la prohibición a la perspectiva consecuencialista del permiso (si no del precepto). Nos dice que es un poco como en el caso del montón de granos, porque no sabemos exactamente cuándo se forma. No podemos especificar la cantidad de frijoles necesarios para dar forma o constituir el montón, y aun así somos capaces de decir en algún momento que el montón está ahí delante de nosotros. No sabemos cuántos granos se deben poner para hacer un montón, y a pesar de ello podemos determinarlo o reconocerlo como tal. En resumen, sería una nueva propuesta de la cuestión filosófica de la "paradoja del sorites" $" 52$.

Con todo, en la "paradoja del sorites", entre la ausencia y la presencia de cierta realidad, en la transición de "calvo" a "melenudo", digamos, no hay solución de continuidad, todo es gradual. No hay un momento, un número

51 Cfr. Kramer, M. H. Michael Moore on torture, morality and law. En Ratio Juris. Vol. Xxv, 2012, 491.

52 Nota del trad.: la "paradoja del sorites" (del griego soros, que significa 'montón') se le atribuye al filósofo Eubúlides de Mileto (siglo Iv a.C.), discípulo de Euclides. Está asociada a los problemas de vaguedad de los términos, esto es, a términos con límites de aplicación poco claros ("borrosos" o "difusos") tales como "montón", "calvo", "alto", "viejo", "azul”, etc. Así, y debido a que el predicado "montón" tiene límites poco claros, parece que ningún grano de trigo puede hacer la diferencia entre un número de granos que sí conforma un montón y un número que no lo hace. Como explica Hyde, dado que un grano de trigo no forma un montón, se deduce que dos granos no lo hacen; y si dos tampoco lo hacen, tampoco tres, y así sucesivamente. Este razonamiento lleva a la conclusión absurda de que al proceder de esta manera no habría nunca un montón frente a nosotros, sin importar el número de granos acumulados. Véase HydE, D. Sorites Paradox. En Standford Encyclopedia of Philosophy. Disponible en: https://plato.stanford.edu/ entries/sorites-paradox/ (último acceso: 07/06/2020). 
específico de cabellos, que matemáticamente nos haga ir más allá de la calvicie. Pero en el caso del que nos habla Moore, en el contexto de la legalidad de la tortura, existe un umbral $\mathrm{N}$ de consecuencias negativas por debajo del cual sería ilegal e injusto torturar. La solución de continuidad que se da aquí, cómo no, y es una dramática. Pero, ¿cuál será el criterio para justificar que $\mathrm{N}$ menos 1 todavía está dentro del umbral deontológico de la prohibición, mientras que $\mathrm{N}$ representa y justifica su superación? Dado que para cualquier $\mathrm{N}$ siempre hay un $\mathrm{N}$ menos 1, debe necesariamente ser una mera determinación arbitraria. Por lo tanto, el "deontólogo del umbral" (como gusta autodefinirse Moore) tendrá que aceptar que el criterio del bien y el mal, de lo justo y lo injusto, de lo lícito y lo ilícito es arbitrario, y, en gran medida, decisionista. Sin embargo, esta es una conclusión que colisiona contra la pretendida certeza y determinación que el deontologismo tiene la ambición de poder ofrecer para garantizar la deliberación moral. En cambio, ahora esta se somete a una evaluación contingente, en gran medida discrecional, derogando cualquier prescripción deontológica.

Como ha sido destacado por un agudo crítico ${ }^{53}$, el "deontólogo del umbral" es tal vez, más sencillamente, un "utilitarista de la regla", esto es, un utilitarista que estructura las consideraciones de utilidad de conformidad con las condiciones generales de aplicación. Por tanto, sería más bien un consecuencialista, por así decir, "indirecto". No todas las consecuencias son determinantes para el consecuencialismo (incluso "directo"), sino solo aquella que tenga cierto peso, que sea especialmente relevante, esto es, que rebase determinado umbral. Así, la referencia a cualquier "umbral" debería ser necesaria y estar presente, para hacerla convincente y conclusiva, en cualquier modelo de razonamiento consecuencialista. En la llamada "deontología del umbral" la diferencia sería, en todo caso, que el umbral es fijo, predeterminado. En esta perspectiva en la que el "umbral" se concibe consecuentemente como la suma de consecuencias negativas no deseadas, el grado de ilegalidad (en relación con el agente) de una determinada conducta se equilibra (y, por lo tanto, se mide) con el grado de consecuencias negativas (indiferentes respecto al agente) de cumplimiento de limitación deontológica ${ }^{54}$.

Todavía se podría decir que la deontología y el consecuencialismo son inconmensurables, porque son concepciones opuestas de lo que es y requiere el ser moral. Para el deontólogo, el individuo nunca es una herramienta o "medio" para el bienestar de los demás, no es "prescindible". Para el consecuencialista, en cambio, cada uno de nosotros es un bien consumible para

53 Véase Alexander, L. Deontology at the threshold. En San Diego Law Review. Vol. XXXVII, 2000, 912. 191.

54 Cfr. Sen, A. Rights and agency. En Philosophy and Public Affairs. Vol. XI, 1982, 190- 
los demás. "That we are resources for others is fundamental to the consequentialist as that we are not resources for others is to the deontologist" 55 .

Respecto a las tesis de Moore, al parecer cuidadosa y seriamente estudiadas en Langley, Virginia, una nueva objeción puede plantearse. Si se permite la tortura de inocentes en ciertos casos, entonces se podría concluir que en esos mismos casos se permite la tortura de todos y cada uno de nosotros. La tortura de los "culpables" está justificada -a los ojos de Moore- como una especie de "legítima defensa", y la del "inocente", porque su prohibición es la causa de una serie de consecuencias negativas. Ahora, dado que "los inocentes" son todos los demás respecto al "culpable", todos ellos podrían ser torturados legítimamente. El terrorista, de hecho, podría ser inducido a confesar al ver la tortura de cualquiera de ellos, y no solo la de un pariente o amigo suyo. La visión de la tortura aplicada a un niño de tres años, incluso si es extranjero y desconocido para el terrorista, podría ser tan insoportable como para presionarlo a revelar la información que quiere extraérsele. No se puede excluir que esto suceda; no puede excluirse que el terrorista se conmueva por el "inocente", quienquiera que sea, y que su compasión pueda ponerse a prueba de la manera más cruel, una vez que los límites de lo deontológicamente lícito hayan sido arrasados y se haya abierto la perspectiva consecuencialista de lo que resulte más útil y eficaz.

Michael Moore se congratula de ser un iusnaturalista, un defensor del derecho natural. Esto puede resumirse para el académico estadounidense en dos tesis principales: (a) una "tesis metaética", para la cual la moral sería objetiva; y (b) una "tesis relacional", según la cual el derecho de los seres humanos ("human law"), esto es, el derecho positivo, estaría íntimamente conectado con la moralidad objetiva ${ }^{56}$. Ahora bien, el "umbral deontológico" defendido por Moore en un examen más detallado revela, como pudimos ver, una versión de "consecuencialismo indirecto", cuando no de consecuencialismo tout court. Esta deontología tiene el efecto fundamental de hacer que la elección moral sea incierta y, de hecho, arbitraria. La determinación del "umbral" que nos permitiría pasar la prohibición deontológica al precepto teleológico (o consecuencialista) está lejos de ser objetiva u objetivamente comprobable. La relevancia de la diferencia en $\mathrm{N}$ y $\mathrm{N}$ menos 1 de las consecuencias negativas, cómo decidir el cambio del consecuente, es bastante inverosímil, además de ser numéricamente vaga e incierta. El requisito de objetividad requerida por la moralidad se debilita, y sin remedio. Como consecuencia, del "derecho natural" queda muy poco. "For us natural lawyers -proclama Moore- morality is there just as solidly as is Mt Everest"

55 AleXANDER. Deontology at the threshold, cit., 912.

56 Moore, M. S. Patrolling the borders of consequentialist justifications. The scope of agent-relative restrictions. En Law and Philosophy. Vol. XXVII, 2007, 35.

57 Ibid., 38. 
preguntarnos qué queda de esa sólida montaña para cualquiera que acepte la tortura de inocentes como legítima.

De hecho, para Moore, la razón práctica y toda la moral están inmersas en un baño de consecuencialismo. Según él, el razonamiento moral se da de conformidad con una estructura de tres niveles, para lo cual existe una base general o fondo consecuencialista, en el que luego se inserta una "superposición", una capa argumentativa, que tiene en cuenta las razones relacionadas con el agente y asumiendo un carácter o tenor deontológico. Tal estrato deontológico puede ser y es superado o derogado por consideraciones consecuencialistas más allá de una cierta suma de consecuencias indeseables producidas por la posición deontológica ("consequentialist override") ${ }^{58}$.

Moore adopta, o más bien parece adoptar, una teoría del "bien intrínseco" a la manera del iusnaturalismo de extracción tomista. Pero rápidamente interpreta tal bien en términos consecuencialistas: "Right action (or right institutions) consists of those actions (institutions) that maximally produce intrinsically good states of affairs" ${ }^{59}$. La acción moral es reconceptualizada como la fabricación de "bienes intrínsecos", no como la manifestación de estos. Entonces aquí -como es evidente-, el uso de "intrínseco" o "intrínsecamente" tiene solo un valor retórico, ya que un bien intrínseco es lo que es necesariamente; no lo que puede producir contingentemente como efecto. La lógica de lo "intrínseco" es diferente a la de la eficiencia que dirige el consecuencialismo. La primera - como ya se dijo- es "necesaria" y puede juzgarse independientemente de una etapa posterior a aquella en la que se predica la bondad "intrínseca". La segunda solo puede ser posible, contingente, y se refiere a un estado posterior que es entonces lo que nos da el criterio de evaluación del estado anterior del cual el siguiente es una consecuencia. Para resumirlo, el "bondad intrínseca" no es susceptible de maximización, ya que no obedece a una lógica gradualista: o se realiza y se manifiesta en la acción o en un determinado estado de cosas, o no se realiza y no se manifiesta, toda vez que es interno y necesario así mismo o no lo es.

Para Moore, por otra parte, el bien intrínseco es susceptible de "maximización". "One can put this as a slogan, surely more of it is better"60. La "maximización", sin embargo, con respecto a una perspectiva ética relacionada con el agente, lo que hace que sea una persona ética, colisiona con el límite insuperable de la individualidad que está en juego en esta perspectiva. El "uno" del individuo no puede maximizarse a sí mismo en "más de uno". En una perspectiva que busca la "maximización de bienes" (incluso si se les llama intrínsecos") la barrera de "uno" obviamente no tiene sentido, toda vez que posibles directivas deontológicas relacionadas con el agente dentro

$\begin{array}{ll}58 & \text { Ibid., } 44 . \\ 59 & \text { Ibid., } 39 . \\ 60 & \text { Ibid. }\end{array}$

Revista Derecho del Estado n..$^{\circ}$, septiembre-diciembre de 2020, pp. 3-29 
de esta perspectiva, si existen, serán de una especie de excepción, y más bien tomarán el valor de los permisos (en lugar de las obligaciones) para abstenerse y derogar las más generales y comprehensivas consideraciones consecuencialistas que se consideran la base del razonamiento moral. "We generally are governed by consequentialist reasons, save when we are permitted or obligated by agent-relative reasons" ${ }^{61}$.

Por lo que respecta a la tortura, todo ello tiene la implicación explícita de que puedo, pero no debo, abstenerme de torturar (siempre debajo del "umbral ético", por supuesto). Se me permite no torturar; pero no tengo ninguna obligación. "No puedo torturar a una persona, incluso si al hacerlo evitaré la tortura (igualmente horrible) de otras dos" 62 .

3.3. Rainer Trapp, un profesor de filosofía en la Universidad de Osnabrück, nos brinda el siguiente ejemplo ${ }^{63}$. En un local vemos repentinamente a dos hombres que sujetan a una mujer con fuerza, mientras que un tercero le da varias cuchilladas en el cuello. La mujer lucha y se queja, pero los hombres que la sujetan e inmovilizan la siguen apretando fuertemente, y el tercer hombre, sin inmutarse, continúa clavándole el cuchillo en la garganta. La escena es sangrienta, y la conducta del tercer hombre revela furia y crueldad. Nuestra reacción ante tal escenario solo puede ser de total rechazo y condena. Luego, advertimos que la mujer ha muerto. Nuestra indignación aumenta y nos hace juzgar a los tres hombres involucrados como criminales merecedores de un castigo severo. Inmediatamente después alguien nos informa, sin embargo, de que la mujer se había tragado algo que la asfixió, y que el tercer hombre con el cuchillo era un médico que intentó hacerle una herida que le permitiera respirar, que los hombres que la agarraban eran comensales que asistían al médico en sus labores de primeros auxilios, y que finalmente la mujer había muerto de asfixia a pesar de la intervención del médico.

En este punto, nuestra valoración de la escena de que fuimos testigos cambia radicalmente. Es su verdadero sentido lo que ha cambiado. Ya no hay indignación ni condena. Habrá más bien reconocimiento por el trabajo del médico y sus asistentes, a pesar del desafortunado desenlace.

En el caso de la tortura -continúa Trapp- podemos enfrentarnos a una situación similar. Juzgamos el sufrimiento infligido al sujeto inmovilizado como algo intolerable y lo condenamos sin ulteriores consideraciones. Pero si tuviéramos que saber más tarde que el sujeto a quien se le inflige el sufrimiento es el secuestrador de un niño cuyo escondite no quiere revelar, y si también se nos dijese que quien le inflige ese sufrimiento es un oficial de policía que

$61 \quad$ Ibid., 41.

62 Ibid.

63 Véase TRAPP, R. Wirklich 'Folter' oder nicht vielmehr selbstverschuldete Rettungsbefragung? En LENZEN, W. (ed.), Ist Folter erlaubt? Juristische und philosophische Aspekte. Paderborn: Mentis, 2007, 95 ss. 
lo hace con el único propósito de salvar la vida del niño secuestrado, entonces tanto la descripción del evento como su calificación normativa (moral) sufrirían una especie de inversión. Lo que antes nos parecía intolerable y condenable, ahora nos parecería lícito y de hecho encomiable. La revocación del juicio viene dada por el registro y la verificación de una serie de datos que desconocíamos anteriormente; y, sobre todo, por la consideración de los motivos que inspiran la conducta examinada.

El motivo de la conducta -defiende Trapp-altera su descripción, la hace diferente, la subvierte. En consecuencia, el motivo de la conducta cambia también su carácter moral. Es como decir que, si sé que un asesinato se comete para salvar la vida de un tercero, ya no estaré frente a un asesinato en el sentido correcto. En todo caso, será un "asesinato", entrecomillado. Ya es algo diferente desde el punto de vista descriptivo, y luego obviamente también y sobre todo desde el punto de vista normativo (moral). El motivo de una conducta -desde esta perspectiva- se superpone a la intención de la conducta misma; allí donde sea noble, moral o compartida, dicha conducta será absuelta. Y se la "absolverá" -debe repetirse- por el hecho de que cambia su descripción, que la convierte en una conducta diferente, en otro hecho. De modo que la llamada "Rettungsfolter", la "tortura de salvación", es decir, la tortura infligida para extraer información posiblemente útil para salvar vidas, ya no sería más tortura en sentido propio.

La conclusión de este razonamiento se hace todavía más explícita por parte de Wolfgang Lenzen, colega de Trappe en Osnabrück. Una cosa, nos dice, es la "tortura genuina", que tiene como objeto y fin la degradación y el sufrimiento de un ser humano; y otra cosa completamente distinta es lo que él denomina "tortura entre comillas", que es un comportamiento cuya finalidad es la salvación de vidas humanas ${ }^{64}$.

Sin embargo, la introducción de esta diferencia entre la imposición deliberada de sufrimiento para humillar y degradar, de un lado, y la imposición de sufrimiento para obtener información considerada relevante para salvar vidas, del otro, es en mi opinión un ejercicio poco filosófico y más de defensor. Básicamente un truco de "leguleyo", una "chicanería". Simplemente es insostenible si nos detenemos a considerar que la "tortura entre comillas" es lo que es, que se debe poner en práctica y luego ser eficaz, es, en primer lugar, "una tortura genuina". Ello es así porque funciona y se produce mediante la aplicación de prácticas dirigidas específicamente a infligir sufrimiento y a humillar y degradar a quienes las padecen. La información, si llega a obtenerse, se logra porque ha pasado el proceso de degradación que ha sido tan intenso que era insoportable para la persona a la que le fue infligido. Pero

64 Véase Lenzen, W. (')Folter('), Menschenwürde und das Recht auf Leben. Nachbetrachtungen zum Fall Daschner. En Lenzen (ed.), Ist Folter Erlaubt?, cit., pp. 199 ss. 
ya había sido diseñada como tal, como un sufrimiento intolerable y como degradación, por el sujeto que la inflige.

Por otro lado, la intención de un acto no es una razón. Uno puede matar con premeditación por la razón más noble. Un esposo puede envenenar a su esposa para heredar su riqueza y utilizarla para salvar a los niños de Sudán del hambre y la desnutrición. En cualquier caso, su acto constituiría un asesinato voluntario, aunque sea concebido o cometido por una razón muy noble. En otras palabras: el motivo no cambia la conducta y su descripción de origen. El motivo no altera el caso; lo que, en cambio, bajo ciertas condiciones puede ser posible para la intención del agente.

La tortura sigue siendo tortura allí donde haya una conducta que se dirige deliberada y directamente a la imposición de un sufrimiento para obtener información, incluso si esto se hace con el noble propósito de salvar una o más vidas humanas. En resumen, la redefinición del acto por medio del motivo no está justificada. Por lo tanto, no se nos permitirá separar la "tortura entre comillas" de la "tortura genuina". La tortura, si es una imposición deliberada de sufrimiento contra un sujeto indefenso, sigue siendo tortura, sea cual sea su motivo. Esto no nos salva, no nos saca de la situación de crueldad premeditada y degradación de la que nos hemos convertido en promotores activos y protagonistas. No cambia la fenomenología de la situación. Por lo tanto, no puede absolvernos.

\section{REFERENCIAS}

Alexander, L. Deontology at the threshold. En San Diego Law Review. Vol. XxxviI, 2000.

Alleg, H. La question. Paris: Gallimard, 1958.

AмÉRY, J. Jenseits von Schuld und Sühne. Bewältigungsversuche eines Überwältigten. Stuttgart: Klett-Cotta, 1977.

Beccaria, C. Dei delitti e delle pene. Pisapia, G. D. (ed.). Milano: Giuffrè, 1973.

Bielefeldt, H. Menschenwürde und Folterverbot. Zur Aufweichung des Folterverbots. Berlin: Deutsches Institut für Menschenrechte, 2007.

BRECHER, B. Torture and the Ticking Bomb. Oxford: Blackwell, 2007.

Brugger, W. Das andere Augen. Folter als zweischlechteste Lösung. En Frankfurter Allgemeine Zeitung. 10 de marzo, 2003.

Brugger, W. Freiheit und Sicherheit. Eine staatstheoretische Skizze mit praktischen Beispielen. Baden-Baden: Nomos, 2004.

Brunkhorst, H. Torture and democracy. En Clucas, B., Johnstone, J. G. y Ward, T. (eds.), Torture: Moral Absolutes and Ambiguities. Baden-Baden: Nomos, 2009.

Forner, J. P. Discurso sobre la tortura. Mollfulleda, S. (ed.). Barcelona: Crítica, 1990. 
Gilead, A. Torture and singularity. En Public Affairs Quarterly. Vol. xIX, 2005.

Ginbar, Y. Why Not Torture Terrorists? Moral, Practical, and Legal Aspects of the 'Ticking Bomb' Justification for Torture. Oxford: Oxford University Press, 2010.

Greenberg, K. J. (ed.). The Torture Debate in America. Cambridge: Cambridge University Press, 2006.

Günther, K. Folter kennt keine Grenze. En Die Zeit. 13 de marzo, 2008.

Hart, H. L. A. Essays on Bentham. Jurisprudence and Political Theory. Oxford: Clarendon, 1982.

Kramer, M. H. Michael Moore on torture, morality and law. En Ratio Juris. Vol. xxv, 2012.

Lenzen, W. (')Folter('), Menschenwürde und das Recht auf Leben. Nachbetrachtungen zum Fall Daschner. En LENZEN, W. (ed.), Ist Folter erlaubt? Juristische und philosophische Aspekte. Paderborn: Mentis, 2007.

Mayerfield, J. In defense of the absolute prohibition of torture. En Public Affairs Quarterly. Vol. XXII, 2008.

Merkel, R. Folter als Notwehr. En Die Zeit. 13 de marzo, 2008.

Moore, M. S. Patrolling the borders of consequentialist justifications. The scope of agentrelative restrictions. En Law and Philosophy. Vol. XXVII, 2007.

Moore, M. S. Torture and the balance of evils. En Israel Law Review. Vol. XXIII, 1989.

Schroeder, D. A child's life or a 'little bit of torture'? State-sanctioned violence and dignity. En Cambridge Quarterly of Healthcare Ethics. Vol. xv, 2006.

SEn, A. Rights and agency. En Philosophy and Public Affairs. Vol. XI, 1982.

TRAPP, R. Wirklich 'Folter' oder nicht vielmehr selbstverschuldete Rettungsbefragung? En Lenzen, W. (ed.), Ist Folter erlaubt? Juristische und philosophische Aspekte. Paderborn: Mentis, 2007.

Twining, W. L. y Twining, P. F. Bentham on torture. En Northern Ireland Legal Quarterly. Vol. xxiv, 1973.

Von Arneth, A. R. Beaumarchais und Sonnenfels. Wien: Wilhelm Braumüller, 1868.

Von Sonnenfels, J. Ueber die Abschaffung der Folter. En Sonnenfels gesammelte Schriften. Vol. 7. Wien: Mit von Baumeisterischen Schriften, 1785.

Von SpeE, F. I processi contro le streghe (Cautio criminalis). A. FoA (ed.). Roma: Salerno, 2004. 